enables me as a psychiatrist to withdraw from treatment knowing the competency of support systems that will not alert services to future problems. Kellett's view that psychiatric services have moved away from the care of psychotic patients to allow more work with neurotic disorders in the community is not my experience of inner city psychiatry where our time is increasingly dominated by the care of serious mental illness.

Many of the problems in the for or against debate could be solved if the organisation of general practice were to change. If GPs become locality-based there could be co-terminous relationships between GP and specialist based on geographical catchment areas. GPs work the way they do for financial not clinical reasons. Choice of GP does not really exist for disabled, vulnerable patients who are practically bound to the local general practice.

Finally, Kellett suggests that mediocrity results from catchment areas stifling competition between consultants. Consultants are well paid professionals who have a contracted responsibility to develop and deliver a quality service with or without competition. Mediocrity is the result of mediocre doctors who believe they can make the minimum of effort once in a permanent position knowing there is lack of sanction against those who do a poor job. Ultimately, if all doctors were good at what they did there wouldn't be a problem. I doubt we can blame the catchment areas for that one.

DAVID N. ANDERSON

Department of Psychogeriatrics,

EMI Directorate, Sir Douglas Crawford Unit,

Mossley Hill Hospital, Park Avenue.

Liverpool L18 8BU

\section{Bias in the assessment of psychiatric emergencies}

Sir: We read with interest the article by Hall $\&$ Deahl on the inadequacies of history taking by trainee psychiatrists in casualty (Psychiatric Bulletin. September 1995, 19, 538-540). While we agree that efforts are merited to increase alcohol and substance abuse histories in all groups, we disagree that this discrepancy is likely to represent ageist or sexist attitudes. The OPCS survey (Goddard, 1991) of drinking habits in the late 1980s (quoted in part in Hall \& Deahl's article) found that $23 \%$ of men and $8 \%$ of women exceeded sensible drinking levels (21 units for men and 14 units for women). Excess drinking showed a decline with increasing age in both sexes. Based on these figures, if a full alcohol history had been taken in all cases at least a further $5.3 \%$ of men and $3.4 \%$ of women would have been identified as exceeding sensible drinking levels. The recording of disorders more likely to occur in a sub-population has a long history in medicine and we do not feel it should necessarily be dismissed as ageist or sexist.

\section{Reference}

GODDARD. E. (1991) Drinking in England and Wales in the late 1980s. London: HMSO/OPCS.

Michel Vanstraelen

Prudhoe Hospital, Prudhoe

RICHARD DUFFETT

Unit of Human Psychopharmocology.

The Royal London Hospital (St Clements), London

Sir: We agree with Vanstraelen \& Duffet that substance use occurs at different levels in different population subgroups. We also agree that it is clinically important to recognise such differences. However, in emergency clinic psychiatry we think that to let information about populations lead us into assumptions about individuals is clinically dangerous. One cannot exclude a diagnosis just because it is unlikely.

IAN HALL

St George's Hospital Medical School.

University of London

MaRTIN DEAHL

St Bartholomew's Hospital Medical College, London

\section{Masters courses in psychiatry}

Sir: We thought that the article by Shoebridge \& McCartney (Psychiatric Bulletin, September 1995. 19, 555-558) raised interesting questions. Having experienced the Cardiff MSc course, we would make the following points:

(1) The development of the MSc course acted as a catalyst to enhance greatly the quality of training for the MRCPsych in Cardiff. Few of us would see any advantage in a return to the 'old' MRCPsych course.

(2) In a rotation which is spread across South Wales, the MSc course has provided a focus and a route of access to the expertise of the academic department in Cardiff for supervision and advice.

(3) The research component means that trainees are encouraged to undertake research and learn research methodology earlier than they might.

(4) At its best, it provides a higher degree in psychiatry and a publication around the 